\title{
MANIFESTAÇÕES PATOLÓGICAS EM EDIFICAÇÕES PÚBLICAS ESCOLARES: ESTUDO DE CASO NA UNIVERSIDADE ESTADUAL DO OESTE DO PARANÁ - CAMPUS CASCAVEL
}

\author{
OLIVEIRA, ANA MARIA DE SOUSA SANTANA \\ Engenheira Civil \\ UNIOESTE \\ Paraná, Brasil \\ asantanadeoliveira@gmail.com
}

\author{
MENIN, THIAGO FELIPE SCHERER \\ Engenheiro Civil \\ Engenium Engenharia \\ Paraná, Brasil \\ shererthiago@hotmail.com
}

\section{RESUMO}

As edificações apresentam problemas patológicos, oriundos das mais diversas causas. Nas edificações públicas, assim como em outras edificações, essas manifestações devem-se a fatores diversos que vão desde a ação de intempéries, até a falta de cuidados e manutenção dos usuários. Em relação as edificações escolares, objeto deste estudo, são locais frequentados diariamente por um grande número de pessoas, condição que as submete às diversas situações que podem desencadear processos patológicos. Seu uso frequente causa um desgaste natural da edificação, como também à deixa suscetível a vandalismo e degradação por uso inadequado. O trabalho tem como objetivo apresentar um levantamento e incidência das principais manifestações patológicas presentes em uma Universidade Pública. O trabalho foi desenvolvido em 06 blocos da universidade, através de vistorias e anamnese com as pessoas responsáveis pelos serviços de manutenção. Na metodologia utilizada também foram feitos registros fotográficos das manifestações patológicas e aplicação de questionários para levantamento as manifestações. Como resultados apresentam-se as principais manifestações presentes nestas edificações, as quais servirão como referência para a definição de possíveis procedimentos de intervenção. O presente trabalho também visa contribuir para que as edificações escolares recebam manutenção adequada e que as obras futuras sejam construídas com maior rigor e atenção, especialmente nos pontos de maiores incidências de manifestações patológicas.

Palavras-chave manifestações patológicas, obras públicas, levantamento.

\begin{abstract}
The buildings present pathological problems, coming from the most diverse causes. In public buildings, as in other buildings, these manifestations are due to various factors such as weather, even the lack of care and maintenance of users. Regarding the school buildings, object of this study, are places frequented daily by many people, a condition that submits them to various situations that can trigger pathological processes. Its frequent use causes a natural wear and tear of the building, as well as leaves it susceptible to vandalism and degradation due to improper use. This paper aims to present a survey and incidence of pathological manifestations present in a Public University. The work was developed in 06 blocks of the university, through surveys and anamnesis with the people responsible for maintenance services. In the methodology used were also made photographic records of the pathologies and application of questionnaires to survey the manifestations. As results are presented the main manifestations present in these buildings, which will serve as a reference for the definition of possible intervention procedures. The present work also aims to contribute so that the school buildings receive proper maintenance and that the future works are built with greater rigor and attention, especially at the points of greatest incidence of pathological manifestations.
\end{abstract}

Keywords: Pathological manifestations, public works, survey.

\section{INTRODUÇÃO}

A construção de estruturas que pudessem ser utilizadas como abrigo sempre foi uma preocupação do homem. Estas estruturas apresentam papel fundamental para possibilitar a realização de atividades e funções desenvolvidas pelos seres humanos. Dessa forma, cada edificação corresponde a um objeto que se caracteriza por sua finalidade, ou seja, são empregadas para uso habitacional, industrial, cultural ou ainda para o uso público (SEGAT, 2015).

Deste modo, é importante que as edificações sejam construídas de forma a atender os seus usuários durante muitos anos. Para que isso seja possível é necessário que as construções apresentem ao longo do tempo condições adequadas ao 
uso para a qual se destinam, resistindo a atuação de agentes externos produzidos pelo ambiente, e ao uso que alteram suas propriedades técnicas iniciais (ANBT NBR 5674, 2012).

No entanto, o despreparo da mão de obra em lidar com o avanço tecnológico no setor de técnicas construtivas e de materiais de construção, possibilitou um aumento significativo do número de manifestações patológicas encontradas em edificações novas. Isso pode ser observado nas edificações públicas do Brasil, onde a presença de anomalias é bastante recorrente e estão associados a diversas causas, como erros nas etapas gerenciais de projetos, execução, assim como no uso inadequados de materiais. Normalmente estes erros promovem, além de falhas, atrasos e prejuízos às empresas e instituições públicas. (IANTAS, 2010).

Pode-se ainda, atribuir a inexistência de manutenções como um dos fatores que favorecem o surgimento precoce de manifestações patológicas, que ocorrem devido à falta de atividades necessárias para garantir que as edificações apresentem níveis satisfatórios de desempenho ao longo do tempo. Isso pode ser resultado, em alguns casos, do processo longo e burocrático pelas quais as edificações públicas passam para adquirir recursos, que seriam destinados a atividades de manutenção e de reformas, prejudicando o andamento dos processos preventivos pelas quais as construções devem passar (OLIVEIRA, 2015).

As edificações públicas apresentam uma particularidade incomum com os outros tipos de construções. Como é frequentada diariamente por um grande número de pessoas favorece um desgaste maior dos elementos e componentes pertencentes a edificação. Portanto, é necessário que os órgãos públicos apresentem um cuidado maior com os aspectos relacionados as atividades de manutenção, possibilitando assim, que as edificações mantenham níveis satisfatórios de desempenho ao longo do tempo.

As edificações são caracterizadas por apresentar ao longo de sua vida útil processos que alteram as suas características iniciais. Estas alterações podem ser resultado do envelhecimento natural que as construções sofrem, mesmo quando submetidas a atividades de manutenção e, além disso, por erros nas etapas dos processos construtivos, que podem gerar o surgimento de manifestações patológicas, diminuindo o desempenho e a durabilidade das edificações (ZUCHETTI, 2015).

No caso de obras públicas, é necessário que as construções apresentem características como funcionalidade, durabilidade e aparência estética agradável, possibilitando que as mesmas possam manter as suas funções por muitos anos, sem que seja necessário realizar manutenções corretivas. No entanto, diversos trabalhos realizados em edificações escolares indicam que a incidência de manifestações patológicas é um problema recorrente e bastante comum neste tipo de obra pública (SCHARDONG \& PAGNUSSAT, 2011).

Nesse sentido, faz-se necessário realizar o levantamento das anomalias nas edificações escolares para identificar e caracterizar as principais manifestações patológicas encontradas, permitindo que seja possível minimizar a sua incidência em projetos futuros. Além disso, este estudo mostra-se como uma fonte para que outros trabalhos busquem encontrar as causas que normalmente provocam o surgimento das falhas nas construções.

Dessa forma, esta pesquisa pretende avaliar, por meio de um levantamento, a incidência das principais manifestações patológicas existentes nos blocos da Unioeste campus Cascavel-PR. Os resultados obtidos permitirão identificar a atual condição que as edificações do campus se encontram, bem como, poderão servir como base para estudos posteriores que visam identificar a origem dos problemas e as etapas mais frequentes que os mesmos ocorrem durante e execução de obras públicas.

\section{REVISÃO BIBLIOGRÁFICA}

A palavra Patologia (páhtos = doença, e logos = estudo), significa "estudo da doença", e é amplamente empregada em vários setores do conhecimento científico. Na construção civil, o termo é utilizado para identificar falhas, defeitos, anomalias ou disfunções que a edificação e seus componentes estão sujeitos devido à perda de desempenho, que pode ocorrer naturalmente ao longo da vida útil, ou de maneira acelerada, gerado por outras razões que tenham origem em qualquer etapa do processo construtivo (CREMONINI, 1988).

Segundo Oliveira (2013), a origem das anomalias nas construções é associada, na grande maioria das vezes, a um conjunto de variáveis, não ficando restrita apenas a um fator. São classificadas de acordo com o processo patológico, os sintomas, a causa que gerou a anomalia e a etapa do processo construtivo que provocou o surgimento da manifestação patológica. 
Helene (2003) afirma que a origem dos problemas patológicos está relacionada a cinco fatores, indicando que a maior incidência das manifestações patológicas ocorre, principalmente, nas etapas de projeto com $40 \%$ e planejamento com $28 \%$, seguidas pelo uso de materiais de baixa qualidade com $18 \%$, uso inadequado das construções representando $10 \%$ e por falhas na etapa de execução com $4 \%$.

O surgimento das manifestações patológicas pode ser compreendido através de alguns conceitos que serão apresentados a seguir.

O conceito de desempenho, é definido pela ABNT NBR 15575 (2013), como a relação que depende da correta definição em projeto de materiais, componentes, elementos e sistemas que juntos irão desempenhar suas funções, com o principal objetivo de satisfazer as condições mínimas de habitabilidade dos usuários.

Já a durabilidade associa-se como a capacidade que as edificações e seus sistemas apresentam de resistir as condições de exposição ambiental, durante um período esperado de tempo. Este conceito está intimamente ligado com as características dos materiais empregados nas construções, que devem, em teoria, apresentar um desempenho igual ou superior aquele definido anteriormente em projeto. Além disso, a durabilidade pode ser proveniente de outros fatores, como ações de manutenção e a utilização dos usuários (CBIC, 2013).

Por fim, o conceito de vida útil pode ser entendido como o período de tempo que a edificações e seus componentes permanecem acima do desempenho mínimo requerido. Este conceito está associado aos cuidados tomados durante as fases de projeto e execução, no uso e nas atividades de manutenção. Além disso o emprego de técnicas construtivas e materiais de qualidade, também são necessárias para impedir que as edificações sofram processos de degradação precoce, diminuindo a probabilidade do surgimento de manifestações patológicas nas edificações (DARDENGO, 2010).

\section{METODOLOGIA}

\subsection{Local de estudo}

O presente trabalho foi desenvolvido em alguns prédios da Universidade Estadual do Oeste do Paraná. A Unioeste é um Instituição de Ensino Superior - (IES), multi-campi, criada em 1994, tendo atualmente oito campi, divididos em cinco cidades do oeste e sudoeste do Paraná. O campus de Cascavel, representado na Figura 1 é um dos três campi da universidade em Cascavel, que ainda conta com a Reitoria e o Hospital Universitário como parte das instalações. O campus de Cascavel, objeto deste estudo, está instalado em um terreno de $123.958,17 \mathrm{~m}^{2}$, localizado na região sul da cidade. Deste total, aproximadamente $59 \mathrm{mil} \mathrm{m}^{2}$ correspondem a área construida.

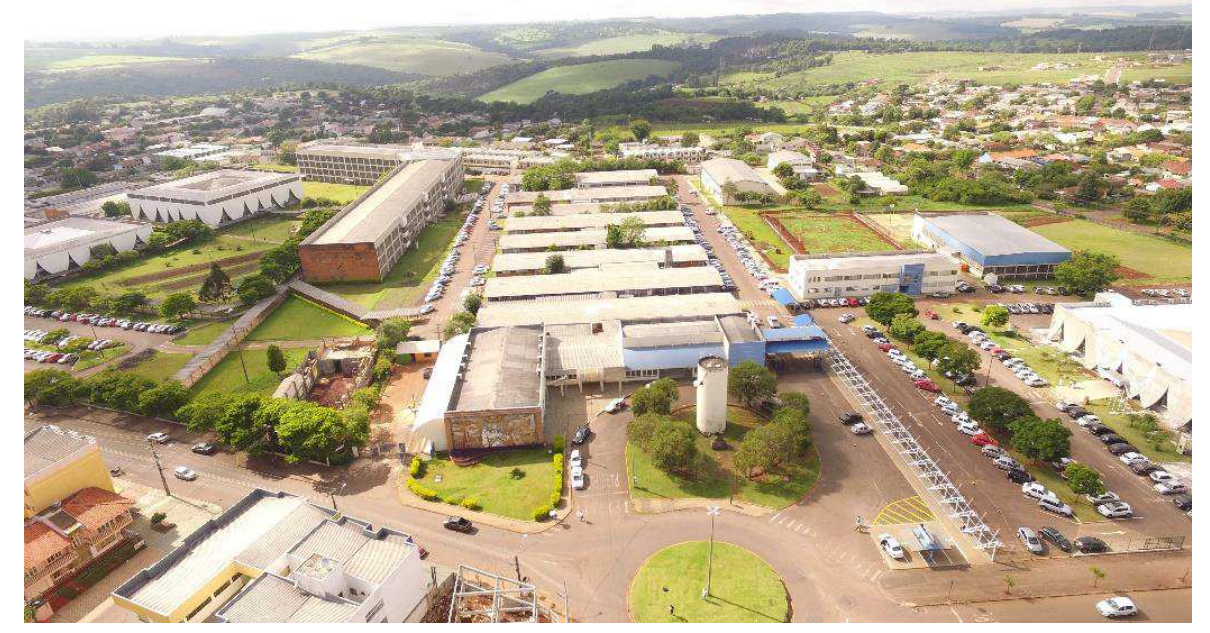

Figura 1: Unioeste-Campus Cascavel. (UNIOESTE, 2016).

\subsection{Escolha das amostras}

Após a definição da proposta de trabalho, foram escolhidos os blocos que fariam parte da pesquisa a ser realizada. O critério de escolha das edificações escolhidas foi baseado a partir de uma vistoria inicial, que teve como finalidade, 
observar dentre os blocos do campus de Cascavel, aqueles apresentavam maior incidência de manifestações patológicas. Após essa vistoria foram escolhidos 5 blocos que fariam parte da pesquisa.

A coleta de dados foi executada na parte interna e externa de 5 prédios do campus de Cascavel: Blocos da antiga FECIVEL (1), Centro de Ciências (2), Biblioteca (3), Centro de Ciências Biológicas e da Saúde - CCBS (4) e Laboratório de Estruturas e Materiais da Engenharia - LEME (5).

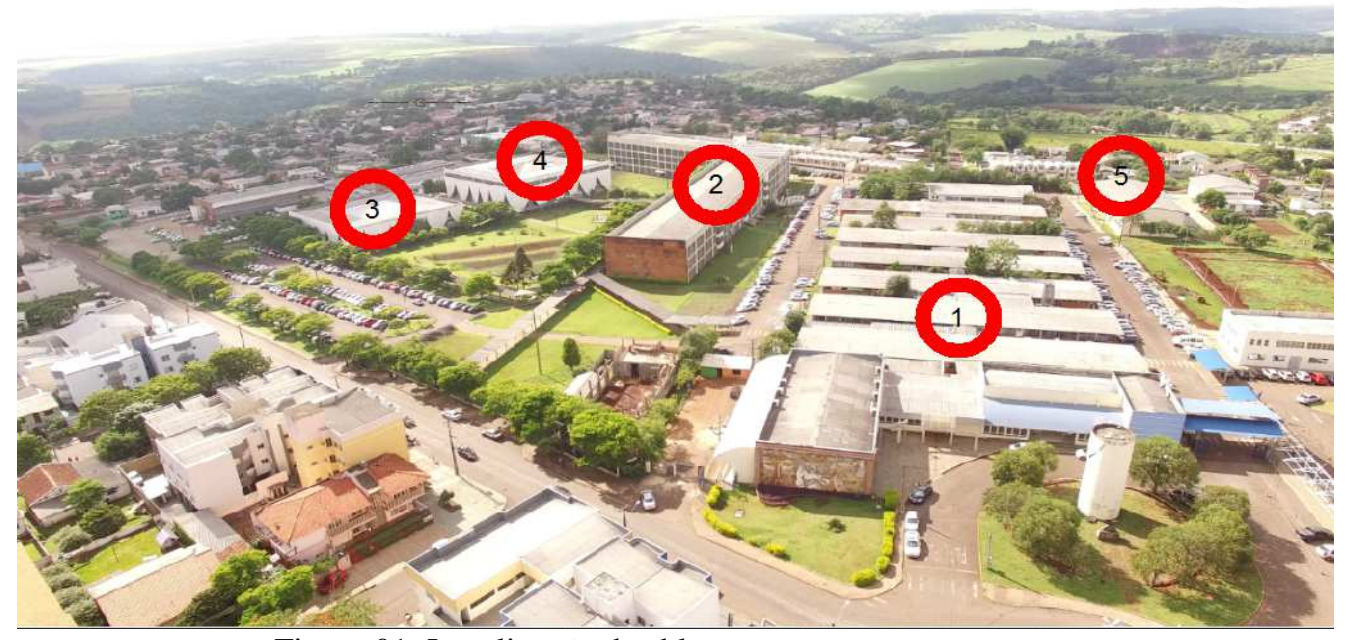

Figura 01: Localização dos blocos pertencentes a amostra

\subsection{Elaboração do Formulário de pesquisa}

Para o desenvolvimento da pesquisa foi elaborado um check list, para a realização das vistorias em cada bloco, com objetivo de permitir o registro das manifestações patológicas encontradas nos ambientes internos e externos das edificações pertencentes ao estudo.

O modelo proposto incialmente foi baseado no estudo de Lima (2010), que caracterizava as possíveis manifestações patológicas em elementos ou componentes da edificação. No entanto, após a realização de uma vistoria para um estudo piloto, decidiu-se realizar algumas mudanças no modelo, com a finalidade de facilitar a coleta de dados e também, para deixar o check list mais detalhado, tornando-o mais completo para a realidade encontrada na Unioeste.

O formulário foi dividido em quatro seções, a primeira relacionada com a descrição de cada bloco da pesquisa, como ano de construção, data da vistoria, horário e condições climáticas encontradas no momento da coleta de dados. Já nas outras três seções encontram-se os elementos e componentes que foram vistoriados (piso, parede e esquadrias). Cada seção foi elaborada de acordo com os tipos de anomalias mais recorrentes encontradas nas edificações, bem como, apresenta informações a respeito dos materiais que foram empregados em cada elemento construtivo dos ambientes, foram atribuídas para cada seção, uma cor que identifica o tipo de elemento construtivo de cada seção do formulário,

\subsection{Coleta de dados - Vistorias}

Durante a coleta de dados foi aplicado o check list desenvolvido para o estudo. Conforme o andamento das vistorias em cada edificação, o formulário foi preenchido de acordo com a identificação das manifestações patológicas encontradas. Além disso, a cada anomalia verificada foi efetuado o registro fotográfico dos dados coletados.

Decidiu-se vistoriar $100 \%$ dos ambientes externos (fachadas) e pelo menos $50 \%$ dos ambientes internos das edificações selecionadas, compreendendo salas de aula, laboratórios, banheiros, setores administrativos, caixas de escada e rampas. Essa porcentagem foi definida em virtude de haver dificuldades de acesso na parte interna de cada bloco, prejudicando a análise dos elementos presentes no check list.

\section{RESULTADOS}

Considerando o objetivo do trabalho, são apresentados os resultados obtidos no levantamento e análise da incidência, assim como nos dados obtidos nos registros fotográficos dos blocos inspecionados. 


\subsection{Caracterização dos blocos}

Apresenta-se as informações gerais de todos os blocos pertencentes ao presente trabalho. A Tabela 1, mostra os resultados obtidos após a coleta de informações e nos permite identificar as características dos blocos analisados.

Tabela 1: Informações gerais sobre dos blocos da amostra

\begin{tabular}{|c|c|c|c|c|c|c|c|}
\hline \multicolumn{2}{|c|}{ Blocos } & Idade & $\begin{array}{c}\mathbf{N}^{\circ} \text { de } \\
\text { Pavimentos }\end{array}$ & $\begin{array}{l}\text { Área do } \\
\text { bloco }\end{array}$ & $\begin{array}{c}\mathbf{N}^{\circ} \mathbf{d e} \\
\text { Ambientes } \\
\text { Internos }\end{array}$ & $\begin{array}{c}\mathbf{N}^{\circ} \text { de } \\
\text { Ambientes } \\
\text { Internos } \\
\text { Visitados }\end{array}$ & $\begin{array}{c}\% \text { de } \\
\text { Ambientes } \\
\text { Internos } \\
\text { Visitados }\end{array}$ \\
\hline \multicolumn{2}{|c|}{ Biblioteca } & 19 anos & 2 & $4.267 \mathrm{~m}^{2}$ & 44 & 26 & 59,1 \\
\hline \multirow{2}{*}{\multicolumn{2}{|c|}{$\begin{array}{c}\text { Blocos Antiga FECIVEL } \\
\text { CCBS }\end{array}$}} & 43 anos & 1 & $8407 \mathrm{~m}^{2}$ & 188 & 119 & 63,3 \\
\hline & & 19 anos & 4 & $7065 \mathrm{~m}^{2}$ & 136 & 76 & 55,9 \\
\hline \multirow{2}{*}{ Centro de Ciências } & Bloco A & 19 anos & 4 & $10590 \mathrm{~m}^{2}$ & 99 & 99 & 64,7 \\
\hline & Bloco B & 06 anos & 4 & $2644 \mathrm{~m}^{2}$ & 47 & 47 & 73,4 \\
\hline \multicolumn{2}{|l|}{ LEME } & 09 anos & 2 & $1121 \mathrm{~m}^{2}$ & 27 & 20 & 74,1 \\
\hline \multicolumn{4}{|c|}{ TOTAL } & $34094 m^{2}$ & 612 & 387 & 63,2 \\
\hline
\end{tabular}

Como a Unioeste é uma instituição de ensino relativamente nova, e algumas de suas instalações foram construídas recentemente, a média de idade dos blocos foi de apenas 19 anos. Dentre os prédios pertencentes a amostra, somente os blocos que fazem parte da antiga FECIVEL possuem idade acima dos 20 anos. Além disso, estes, são os únicos que possuem apenas um pavimento.

Pode-se observar que em todos os blocos a porcentagem de ambientes internos vistoriadas foi superior a $50 \%$ do total de ambientes existentes. É importante destacar que na região externa $100 \%$ das fachadas foram avaliadas

\subsection{Incidência de manifestações patológicas por elemento construtivo}

Após realizar a análise dos dados coletados nas vistorias foi elaborado um gráfico representado pela Figura 3 que apresenta a incidência das manifestações patológicas nos elementos construtivos e onde se manifestaram.

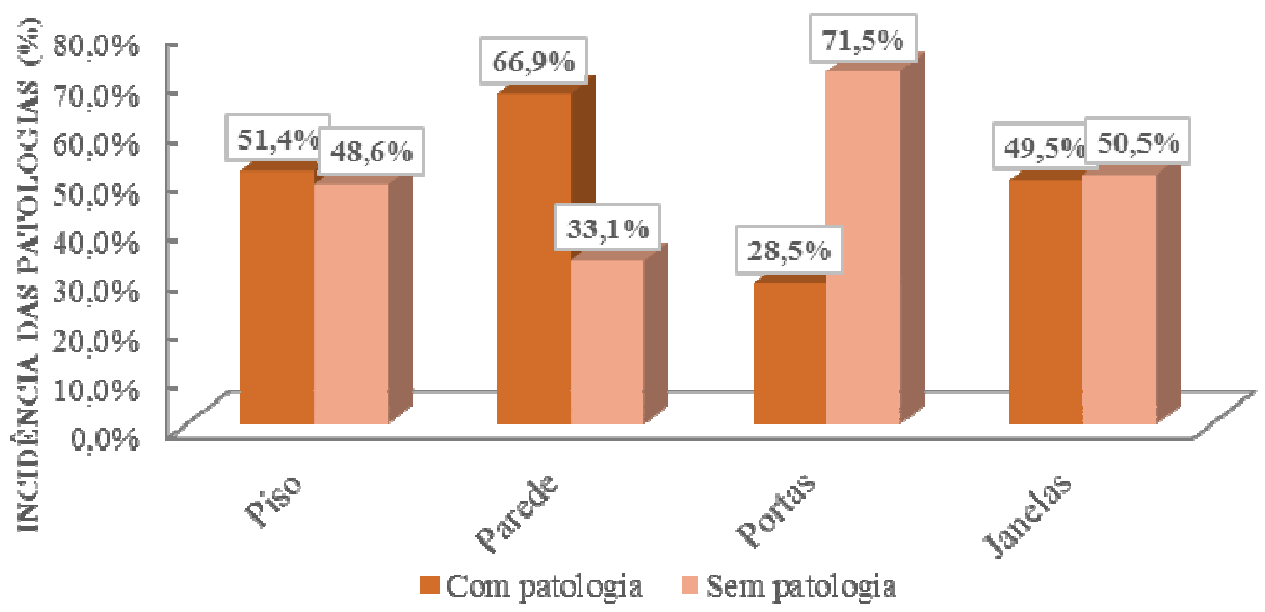

Figura 3: Incidência geral de manifestações patológicas por elementos construtivos.

Pode-se verificar que a maior incidência de manifestações patológicas nos blocos da Unioeste foi encontrada nas paredes, com ocorrência em $66,9 \%$ de todos os ambientes visitados. Nesse elemento construtivo, foram consideradas as paredes de alvenaria convencional com pintura, paredes de alvenaria convencional com revestimento cerâmico e as paredes de alvenaria aparente.

Em seguida, as manifestações patológicas envolvendo pisos apresentaram incidência de 51,4\%. Por fim, tem-se os problemas relacionados às esquadrias, com 49,5\% de incidência nas janelas e 28,5\% de incidência nas portas. Apesar da 
maior incidência ocorrida nos blocos ser das manifestações patológicas envolvendo as paredes, o que chama atenção é ocorrência dessas envolvendo as esquadrias, principalmente os relacionados às janelas.

Em todas as edificações vistoriadas, funcionários e estudantes da universidade relataram problemas com o funcionamento das mesmas. Foi possível observar em diversos ambientes que estes elementos estavam deteriorados, com problemas de pintura e de ferrugem, devido supostamente, à falta de atividades de manutenção.

\subsection{Incidência geral por tipologia de manifestação patológica}

Para apresentar os resultados relativos à tipologia de manifestações patológicas, foi elaborado um gráfico representado na Figura 4, apresentando a incidência dos tipos de manifestações patológicas detectadas e a porcentagem que representa em relação ao total dos registros.

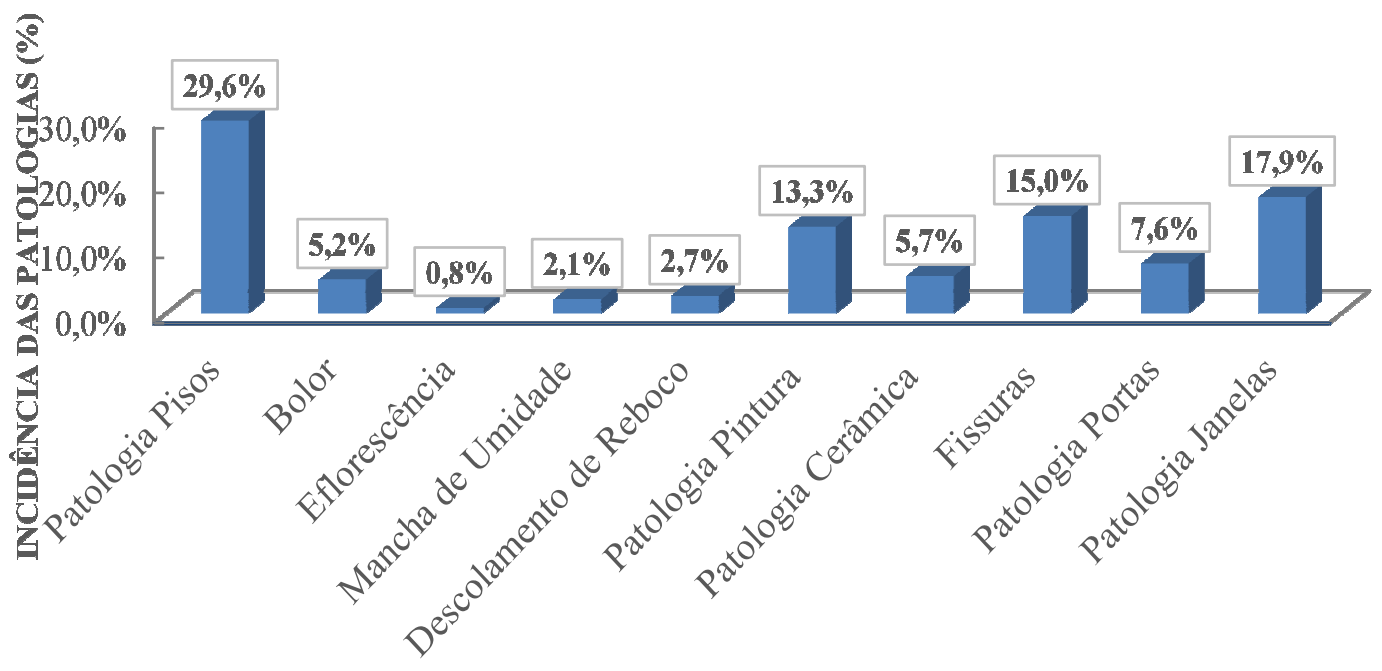

Figura 4: Incidência geral de manifestações patológicas por tipologia.

A tipologia de manifestação patológica de maior destaque nos blocos da Unioeste é o grupo de manifestações patológicas que aparecem nos pisos, com 29,6\% das incidências totais. Neste grupo tem-se 12,3\% de pisos descolados, $17,6 \%$ de pisos danificados, $41,5 \%$ de pisos manchados, $27,1 \%$ de pisos desgastados e 1,4\% de pisos fissurados. Já a manifestação patológica menos incidente nos prédios, foi a eflorescência com $0,8 \%$ das incidências totais.

Além disso, é importante destacar o grupo das manifestações patológicas nas janelas com 17,9\% e o grupo das fissuras com $15,0 \%$ das incidências totais. No primeiro grupo tem-se 56,9\% de janelas com problemas de pintura, 26,5\% de janelas danificadas e 16,5\% de janelas enferrujadas. Já no segundo grupo tem-se 23,8\% de fissuras inclinadas, 15,2\% de fissuras mapeadas, $32,0 \%$ de fissuras verticais e $29,0 \%$ de fissuras horizontais.

Pode-se observar que os resultados obtidos fornecem a configuração encontrada na maioria dos blocos vistoriados. Dentre todas as tipologias presentes no check list, foram as manifestações patológicas relacionadas com os grupos dos pisos, fissuras e manifestações patológicas envolvendo as esquadrias, que mais apresentaram ocorrência durante a coleta de dados.

Alguns exemplos de manifestações patológicas encontradas nos ambientes vistoriados da Unioeste, podem ser vistos na Figura 01. Para facilitar a identificação foram utilizadas as seguintes denominações de acordo com cada imagem: 1) Piso manchado no Centro de Ciências - Bloco A; 2) Piso descolado no Centro de Ciências - Bloco B; 3) Piso desgastado no LEME; 4) Fissuras na fachada da Biblioteca; 5) Fissura inclinada no bloco da antiga FECIVEL; 6) Janela enferrujada no bloco da antiga FECIVEL. 

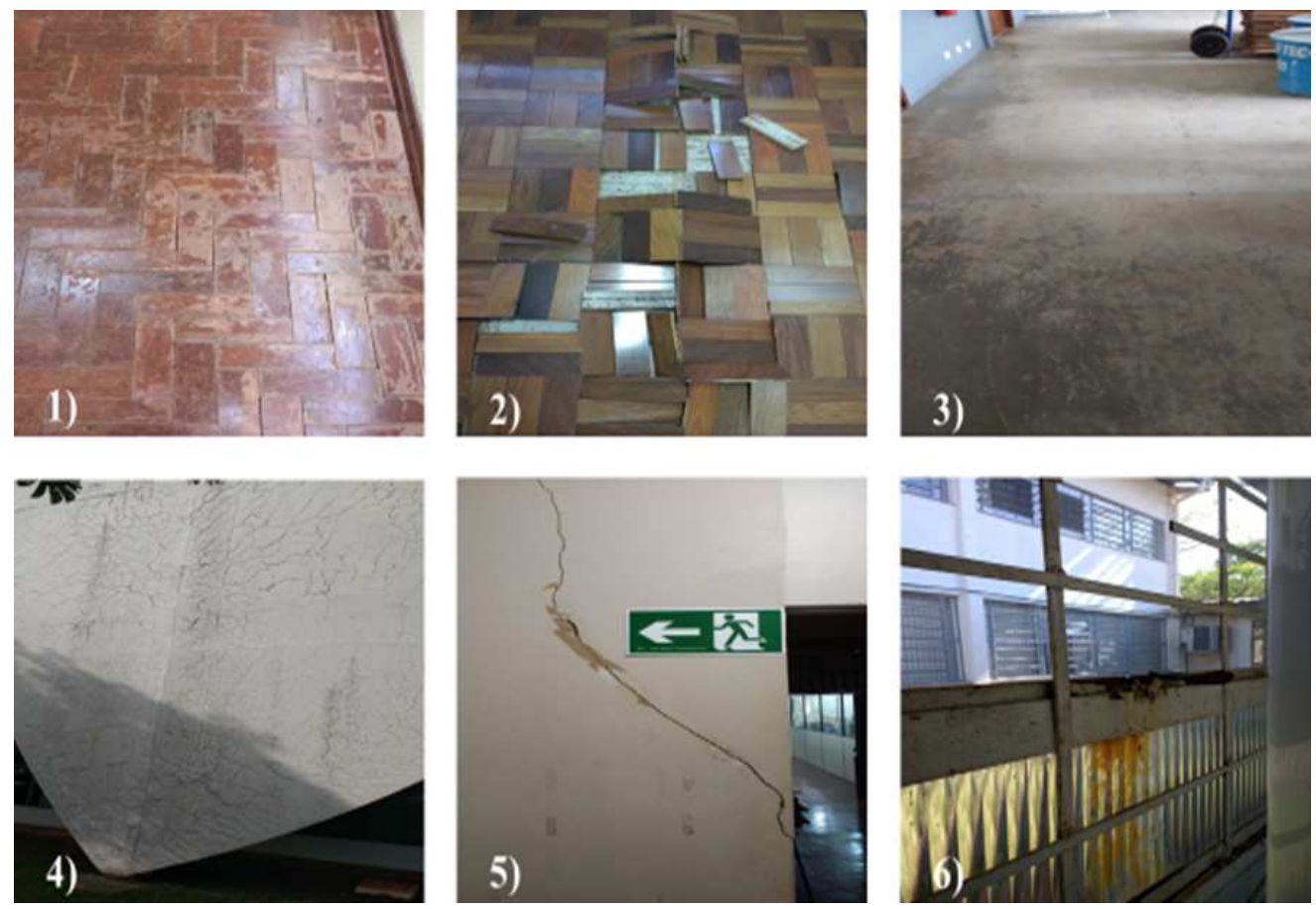

Figura 01: Manifestações patológicas encontradas nos blocos pertencentes à pesquisa

\subsection{Incidência por tipologia de manifestação patológica nos ambientes externos}

A manifestação patológica mais encontrada durante a coleta de dados foi o bolor com $29,7 \%$ e o grupo das fissuras com $28,2 \%$ das incidências totais. Nesse grupo temos, $9,9 \%$ de fissuras inclinadas, 33,3\% de fissuras mapeadas, $31,5 \%$ de fissuras verticais e $25,2 \%$ de fissuras horizontais. Já as manifestações patológicas menos detectadas foram as eflorescências e o grupo das manifestações patológicas nas cerâmicas, ambos com 1,4\% das incidências totais.

É importante destacar também, a elevada incidência do grupo das manifestações patológicas nas janelas com 14,8\% das incidências totais. Além disso, com 15,8\% das ocorrências nos ambientes externos, o grupo das manifestações patológicas nas pinturas apresentou uma porcentagem considerável de manifestações patológicas. Nesse grupo temos, $7,9 \%$ de pintura com bolhas, $60,5 \%$ de descolamento de pintura e $31,6 \%$ de pintura com manchas do total manifestações patológicas nos ambientes externos da Unioeste. 

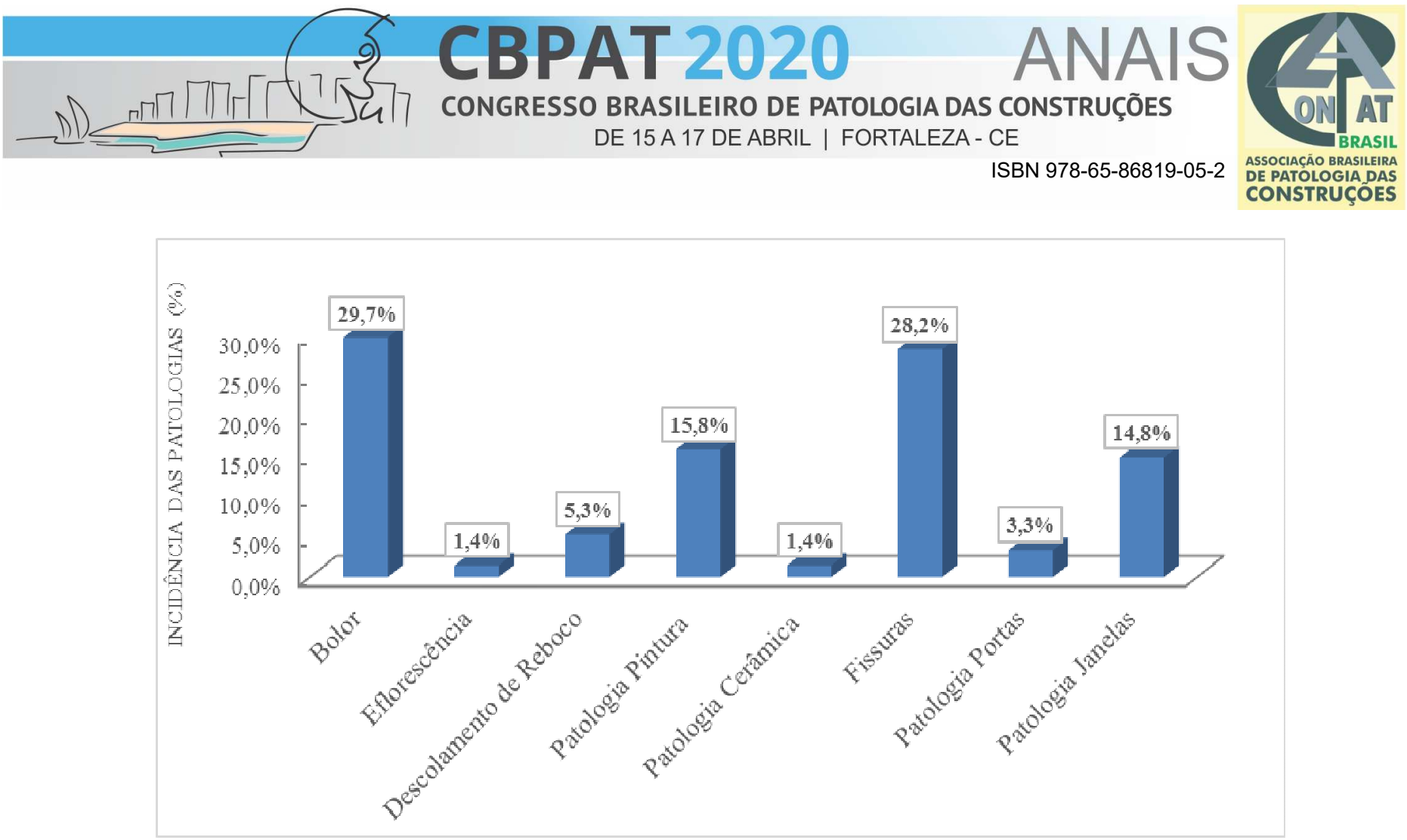

Figura 1: Incidência geral de manifestações patológicas nos ambientes externos por tipologia

Alguns exemplos de manifestações patológicas encontradas na região externa durante as vistorias podem ser analisados na Figura 6. Para facilitar a identificação das manifestações patológicas foram utilizadas as seguintes denominações de acordo com cada imagem: 1) Bolor e fissuras no bloco da antiga FECIVEL; 2) Fissuras e descolamento de pintura no Centro de Ciências - Bloco A; 3) Fissuras e janela enferrujada no bloco da antiga FECIVEL.
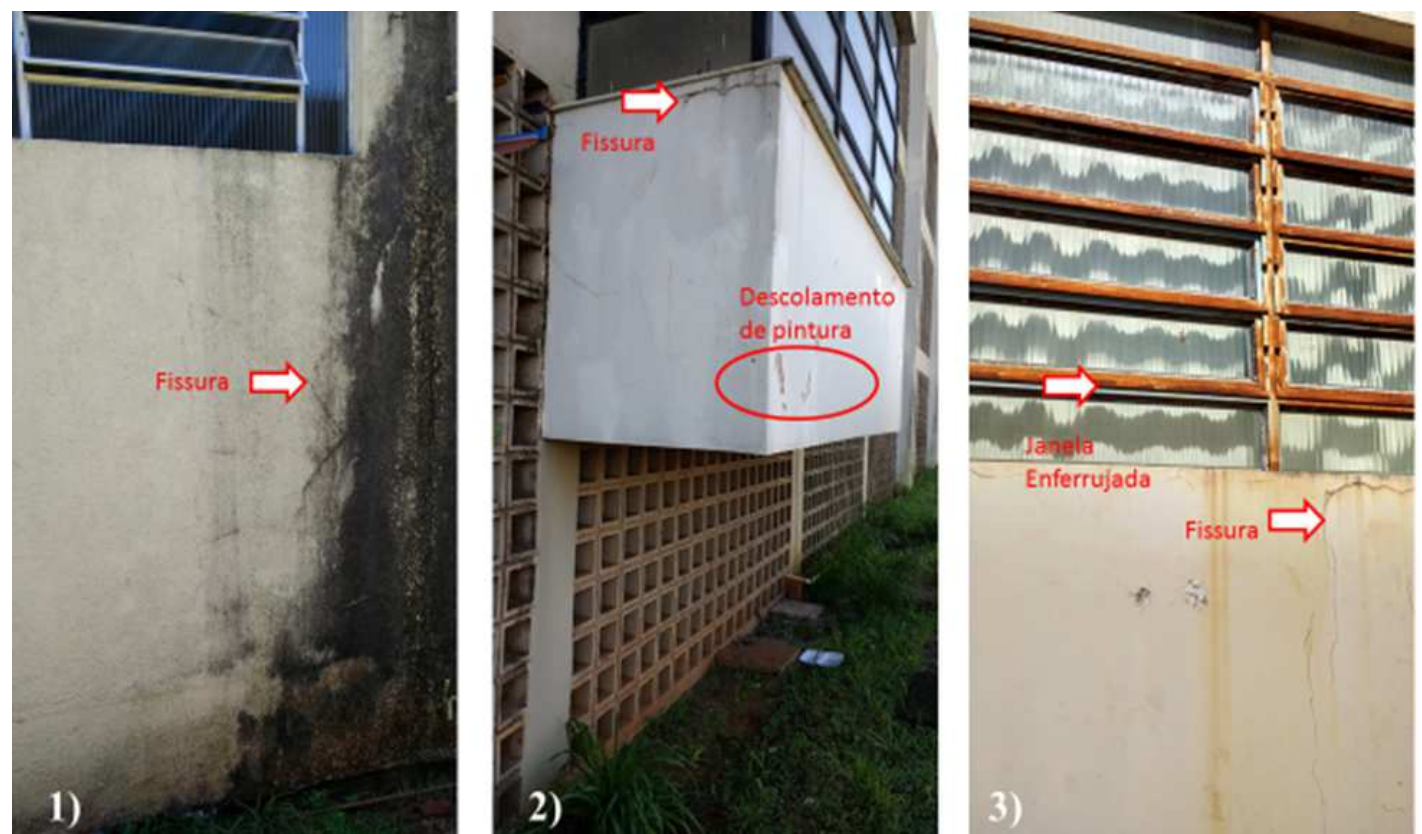

Figura 6: Manifestações patológicas encontradas na região externa dos blocos

Estas ocorrências são justificadas, principalmente, pela atuação dos agentes externos nas edificações, que aliados à falta de manutenção e utilização de materiais com baixa qualidade na execução das obras favorecem o surgimento de manifestações patológicas. Portanto, é necessário ter um maior controle em relação ao tipo de material empregado durante a construção, de modo que estes elementos sejam duráveis e mais resistentes. 


\subsection{Incidência por tipologia de manifestação patológica nos ambientes internos}

Na Figura 37, observa-se que as manifestações patológicas nos pisos e nas paredes se destacam dos demais elementos construtivos, ambos com mais de $60 \%$ de incidência nos ambientes internos visitados. Em seguida, as manifestações patológicas envolvendo as janelas apresentaram uma incidência de 18,9\%. Por fim, temos os problemas relacionados com as portas, com apenas $8,7 \%$ de incidência.

Os resultados indicaram que 24,5\% das incidências totais de manifestações patológicas estão relacionadas ao piso. Neste grupo tem-se 12,3\% de pisos descolados, 17,6\% de pisos danificados, 41,5\% de pisos manchados, $27,1 \%$ de pisos desgastados e 1,4\% de pisos fissurados. As eflorescências, porém, apresentam-se como a patologia de menor incidência na região interna dos prédios, com apenas com $1,2 \%$ do total.

$\mathrm{Na}$ área interna, nota-se que as manifestações patológicas nos pisos foram as que mais incidiram nos blocos da Unioeste. Quase todas as edificações que fazem parte do presente estudo apresentaram índices elevados de problemas relacionados com o piso. O Bloco B do Centro de Ciências, foi o único que teve baixa incidências de manifestações patológicas nesse elemento construtivo, foto que se justifica, principalmente, pela baixa idade do prédio, apenas 6 anos

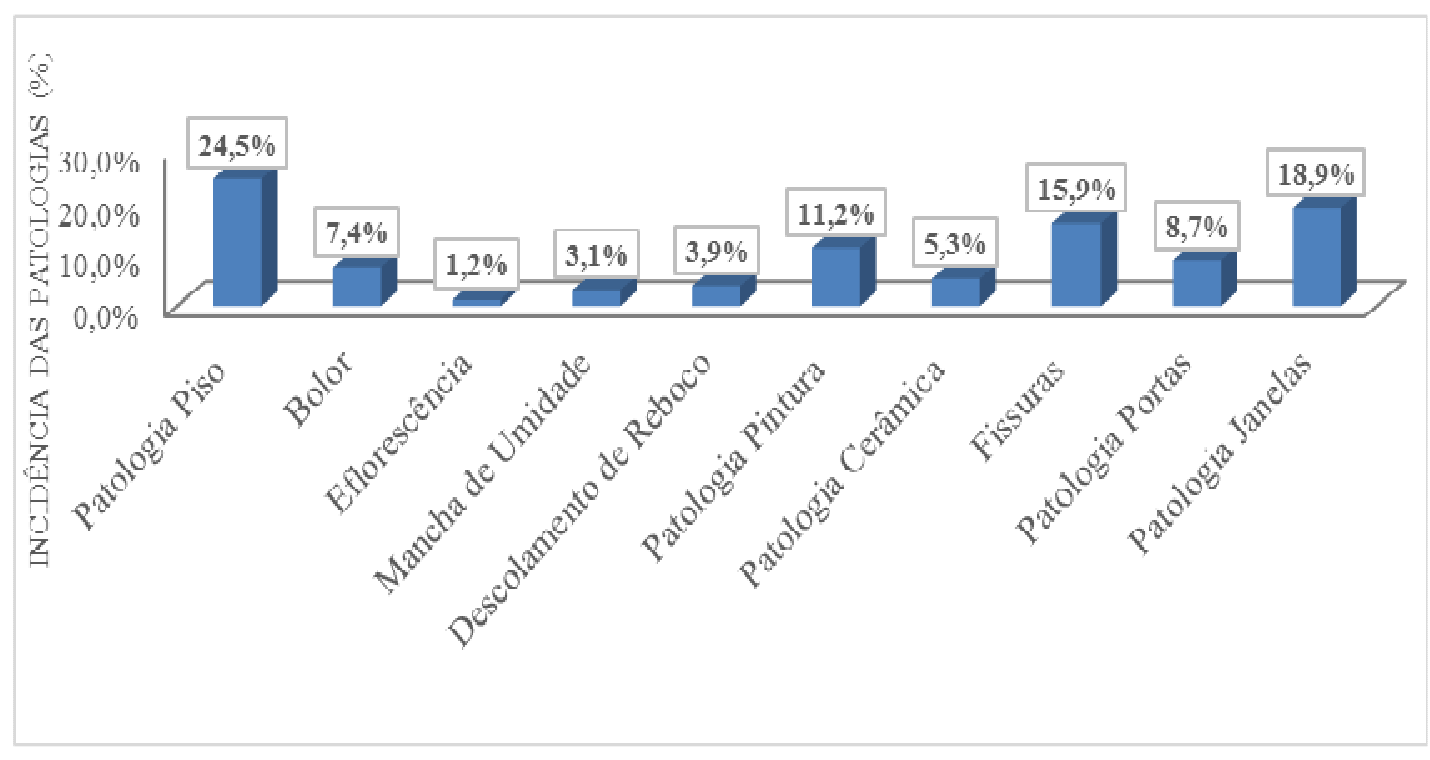

Figura 1: Incidência geral de manifestações patológicas nos ambientes internos por elemento construtivo

Contudo, merecem destaque, a incidência do grupo das manifestações patológicas nas janelas com 18,9\% dos registros totais e as manifestações patológicas do grupo das fissuras. Assim como ocorreu nas regiões externas dos prédios, o grupo das fissuras chamou atenção pela porcentagem encontrada nos ambientes internos dos blocos, com 15,9\% das incidências totais. Nesse grupo tem-se, 23,8\% de fissuras inclinadas, 15,2\% de fissuras mapeadas, 32,0\% de fissuras verticais e $29,0 \%$ de fissuras horizontais das incidências gerais nos ambientes internos da Unioeste.

As paredes das regiões internas, foram os elementos construtivos onde incidiram a maior quantidade de manifestações patológicas. Porém, as fissuras apresentaram uma queda de aproximadamente $13 \%$ de ocorrência quando comparado à análise das regiões externas. Isso pode ser explicado, dentre outros fatores, pelo baixo contato dos ambientes internos à atuação de agentes agressivos. 

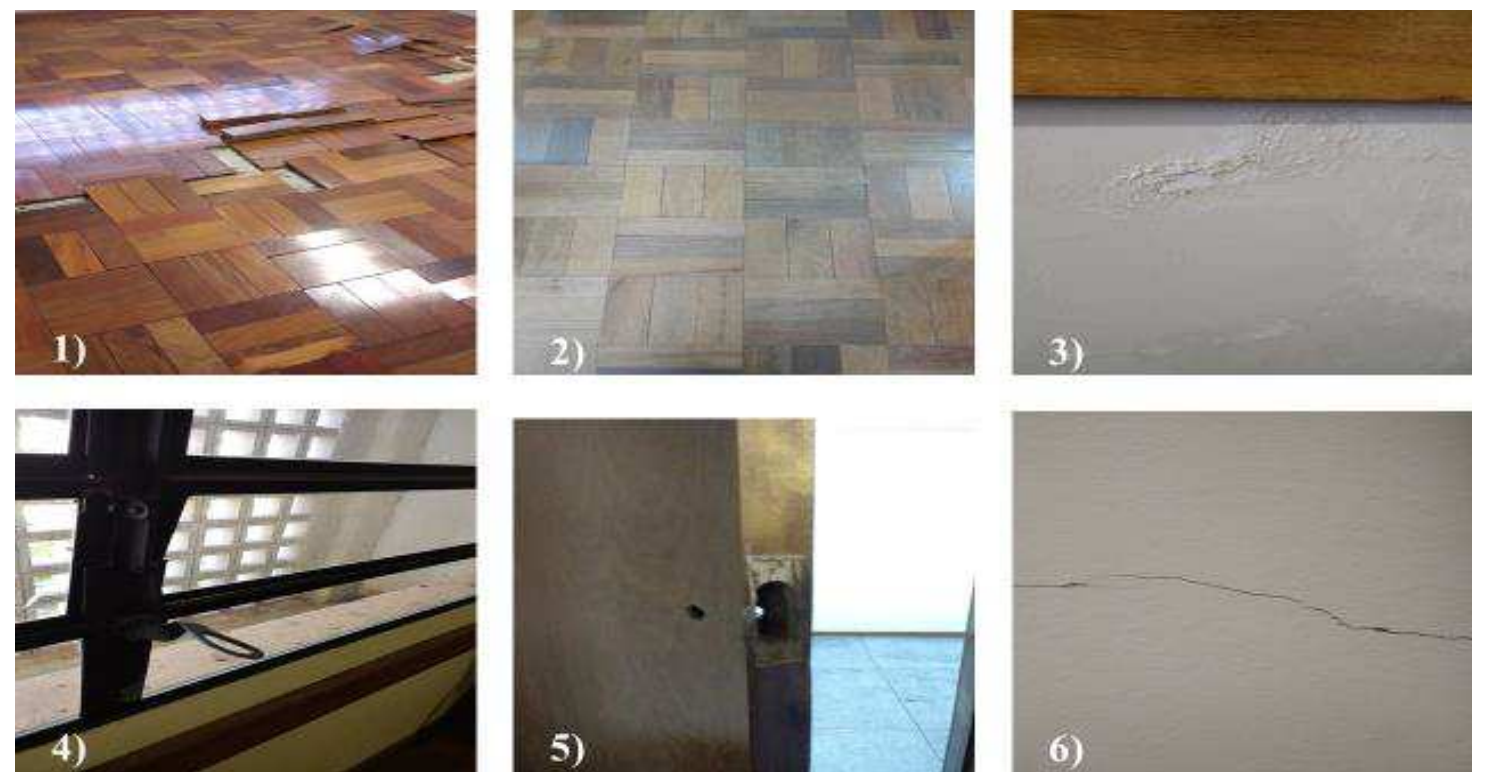

Figura 7 : Manifestações patológicas encontradas na região interna dos blocos da Unioeste

Alguns exemplos de manifestações patológicas encontradas na região interna dos blocos durante as vistorias podem ser analisados na Figura 03. Para facilitar a identificação das manifestações foram utilizadas as seguintes denominações de acordo com cada imagem: 1) Piso manchado na Biblioteca; 2) Parede com bolor, bolhas na pintura e descolamento de reboco no CCBS; 3) Parede com fissura horizontal no Centro de Ciências - Bloco A

\subsection{Análise individual das manifestações patológicas por bloco}

Nesta seção são apresentados os resultados obtidos, individualmente nos blocos vistoriados. Foi necessária esta análise de cada bloco pois as edificações apresentam usos (laboratório, salas de aula, setor administrativo) e características construtivas diferentes, como o tipo de piso e revestimento externo/interno.

A Figura 8 apresenta a incidência de manifestações patológicas em cada edificação da pesquisa de uma forma geral. As porcentagens foram determinadas em relação ao número total de manifestações patológicas identificadas nos ambientes internos e externos.

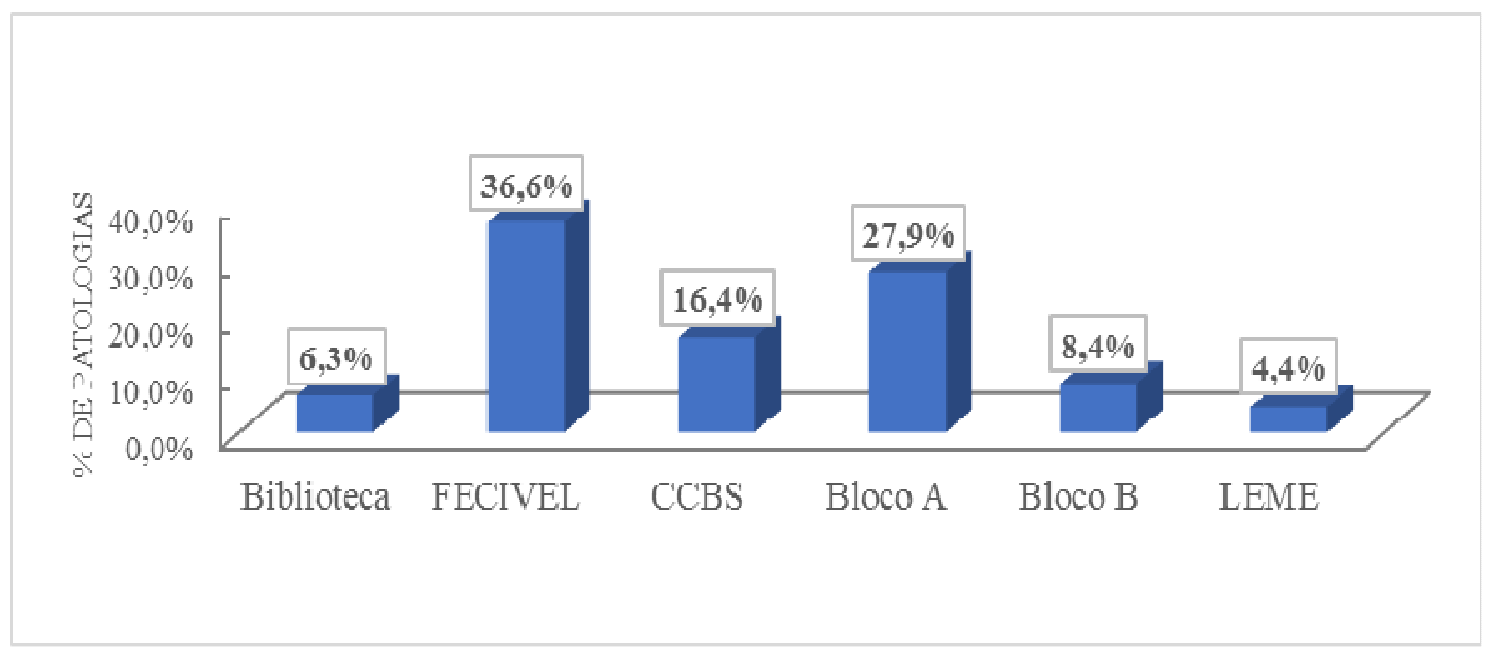

Figura 04: Manifestações patológicas encontradas em cada bloco pertencente a pesquisa

Observa-se que os blocos da antiga FECIVEL apresentaram a maior incidência com 36,6\% dos registros totais. Este é o bloco mais antigo da Unioeste, construído na década de 70, e constantemente reformado para adaptar os ambientes internos existentes em outros setores da universidade, como salas de aula, laboratórios e setores administrativos. Porém, 
mesmo submetido a várias reformas o bloco ainda obteve a maior porcentagem de manifestações patológicas, com destaque para as encontradas nas fachadas.

No LEME foi encontrada a menor quantidade de manifestações patológicas, representando 4,4\% dos registros totais. Com nove anos desde a sua inauguração, a presente edificação é uma das mais novas construções da Unioeste. No entanto, merece destaque o índice de manifestações patológicas encontradas nos pisos durante as vistorias, que foi o maior índice entre todos os edifícios da pesquisa.

\subsection{Análise comparativa entre idade e incidência de manifestação patológica}

Para apresentar um comparativo entre a idade dos blocos e a porcentagem de incidência em relação a cada tipologia, foi criado o gráfico da Figura 9. Neste gráfico, os prédios foram divididos por faixas de idade, apresentando a incidência em relação ao número total dos registros de manifestações patológicas encontrados nas vistorias.

Pode-se observar que em todas as tipologias do check list, os blocos com idade entre 15 e 30 anos e os com idade superior a 30 anos apresentaram a maior porcentagem em relação aos blocos mais novos.

No entanto, com relação as fissuras, a idade dos blocos não é necessariamente o principal fator relacionado ao seu surgimento, uma vez que as fissuras podem ter origem nas etapas construtivas, ou na utilização de materiais com baixa qualidade. Isso pode ser observado nas análises do gráfico da Figura 82, uma vez que a incidência de fissuras foi similar nos blocos com idade superior a 30 anos e nos blocos com idade entre 15 a 30 anos.

O que chama a atenção é o percentual de manifestações patológicas nas cerâmicas dos blocos com idade entre 15 a 30 anos com incidência de 87,3\% dos registros totais. Pode-se observar que durante as vistorias o CCBS, que possui 19 anos de idade, foi o bloco onde foi encontrado índices elevados de manifestações patológicas nos revestimentos cerâmicos, motivo que favoreceu a maior porcentagem das manifestações nesta faixa de idade. Além disso, merece destaque a incidência de manifestações patológicas nos pisos com 62,3\% e as manifestações patológicas nas portas e nas janelas, ambas com mais de 50,0\% do total de registros na faixa de idade entre 15 a 30 anos.

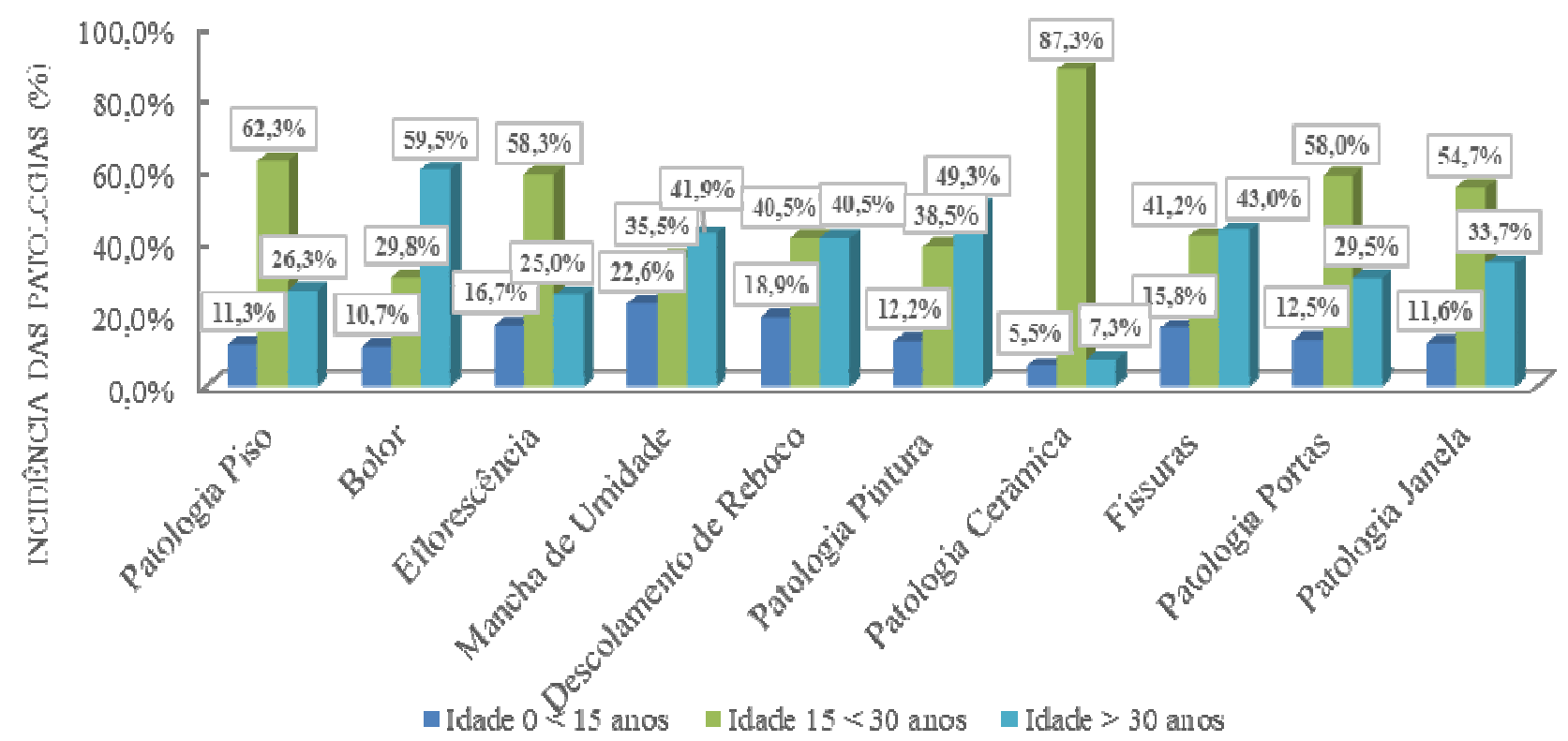

Figura 9: Relação entre a idade e as manifestações patológicas

Analisando o gráfico, pode-se verificar que nos blocos com idade superior a 30 anos, as manifestações patológicas mais identificadas foram os bolores com 59,5\%, patologia das pinturas com 49,3\%, fissuras com 43,0\% e manchas de umidade com $41,9 \%$ do total de incidências. Isso pode estar pode estar relacionado, principalmente ao período de tempo em que os blocos estão submetidos a ação de agentes agressivos, como a umidade e a temperatura, que são os principais fatores que provocam surgimento de bolor e de problemas de pintura.

No entanto, com relação as fissuras, a idade dos blocos não é necessariamente o principal fator relacionado ao seu surgimento, uma vez que as fissuras podem ter origem nas etapas construtivas, ou na utilização de materiais com baixa 
qualidade, uma vez que a incidência de fissuras foi similar nos blocos com idade superior a 30 anos e nos blocos com idade entre 15 a 30 anos. O que chama a atenção é o percentual de manifestações patológicas nas cerâmicas dos blocos com idade entre 15 a 30 anos com incidência de $87,3 \%$ dos registros totais.

Pode-se observar que durante as vistorias o CCBS, que possui 19 anos de idade, foi encontrado índices elevados de manifestações patológicas nos revestimentos cerâmicos, motivo que favoreceu a maior porcentagem nesta faixa de idade. Além disso, merece destaque a incidência de manifestações patológicas nos pisos com 62,3\% e as manifestações nas portas e nas janelas, ambas com mais de 50,0\% do total de registros na faixa de idade entre 15 a 30 anos.

Por fim, no presente trabalho não foi possível verificar uma relação direta da idade com a incidência de manifestações patológicas nos prédios da Unioeste. Observou-se que a maior ocorrência de manifestações patológicas está nos blocos com idade entre 15 a 30, exceto em algumas tipologias que estão mais presentes nos blocos com idade superior a 30 anos. Já blocos com idade inferior a 15 anos, nenhuma manifestação patológica apresentou porcentagens superiores de incidência comparado as outras idades.

\section{CONSIDERAÇÕES FINAIS}

No geral, observou-se que as manifestações patológicas mais encontradas durante as vistorias foi o grupo das manifestações patológicas relacionadas com o piso, representando $29,6 \%$ dos registros totais. Já a manifestação patológica que menos incidiu foram as eflorescências representando $0,8 \%$ das incidências totais.

Nas regiões externas, o bolor e o grupo das fissuras apresentaram a maior porcentagem de manifestações patológicas, ambos representando aproximadamente $30,0 \%$ dos registros totais. Já as manifestações patológicas que menos incidiram foram as eflorescências e o grupo das manifestações patológicas na cerâmica, ambos representando 1,4\% das incidências totais. Ainda referente aos ambientes externos, a Biblioteca e os blocos da antiga FECIVEL se destacaram pelo pela presença de grande número dessas manifestações acima citadas.

Nos ambientes internos, a manifestação patológica mais encontrada durante a coleta de dados foi a do grupo das manifestações patológicas relacionadas com o piso representando $24,5 \%$ dos registros totais. Já a manifestação patológica que menos incidiu foi a eflorescência representando 1,2\% das incidências totais. $\mathrm{O}$ único bloco onde as manifestações patológicas dos pisos não foram predominantes foi o Bloco B do Centro de Ciências, que é o prédio mais novo da pesquisa. Pode-se verificar também com as análises dos dados que os blocos da antiga FECIVEL apresentaram o maior número de manifestações patológicas, representando 36,6\% do total de registros feitos. Já o bloco que apresentou o menor número de manifestações foi o LEME com 4,4\% das incidências totais.

De uma forma geral, pode-se verificar que os blocos selecionados para a pesquisa apresentaram índices significativos de manifestações patológicas, indicando a existência de possíveis problemas de mau uso, falta de manutenção e até mesmo de falhas nas etapas construtivas que favoreceram o surgimento dessas manifestações.

Portanto, decidiu-se realizar a coleta de informações em pelo menos $50 \%$ dos ambientes internos dos blocos selecionados para o estudo. Já nas regiões externas as vistorias foram realizadas em 100\% das fachadas dos prédios.

Finalizada a etapa de coleta dos dados, observou-se que as manifestações patológicas mais encontradas durante as vistorias foi o grupo das manifestações patológicas relacionadas com o piso representando 29,6\% dos registros totais, em todas as edificações selecionadas para o estudo. Já a manifestação patológica que menos incidiu foi a eflorescência representando $0,8 \%$ das incidências totais.

Nas regiões externas, o bolor e o grupo das fissuras apresentaram a maior porcentagem de incidência, ambos representando aproximadamente 30,0\% dos registros totais. Já as manifestações patológicas que menos incidiram foram as eflorescências e o grupo das manifestações patológicas na cerâmica, ambos representando 1,4\% das incidências totais. Ainda referente aos ambientes externos, a Biblioteca e os blocos da antiga FECIVEL se destacaram pelo grande número das manifestações patológicas acima citadas.

Nos ambientes internos, a manifestação patológica mais encontrada durante a coleta de dados foi a do grupo das manifestações patológicas relacionadas com o piso representando $24,5 \%$ dos registros totais. Já a manifestação patológica que menos incidiu foi a eflorescência representando 1,2\% das incidências totais. O único bloco onde as manifestações patológicas dos pisos não foram predominantes foi o Bloco B do Centro de Ciências, que é o prédio mais novo da pesquisa. 
Com as análises dos dados pode-se verificar que os blocos da antiga FECIVEL apresentaram o maior número de manifestações patológicas, representando 36,6\% do total de registros feitos. Já o bloco que apresentou o menor número de manifestações patológicas foi o LEME com 4,4\% das incidências totais.

\section{REFERÊNCIAS}

ASSOCIAÇÃO BRASILEIRA DE NORMAS TÉCNICAS - ABNT. NBR 5674: Manutenção de edificações Requisito para o sistema de gestão de manutenção. Rio de Janeiro, jan 2012. 34 p.

ASSOCIAÇÃO BRASILEIRA DE NORMAS TÉCNICAS - ABNT. NBR 15575: Edificações habitacionais Desempenho. Rio de Janeiro, jul 2013. 63 p.

CIBIC - CÂMARA BRASILEIRA DA INDÚSTRIA DA CONSTRUCÃO. Desempenho de edificações habitacionais Guia orientativo para atendimento à norma ABNT 15575/2013. 311p. 2ª Ed., Fortaleza, 2013.

CREMONINI, R. A. Incidência de manifestações patológicas em unidades escolares na região de Porto Alegre Recomendação para projeto, execução e manutenção. 1988. 169f. Dissertação (Mestrado) - Curso de Engenharia Civil. Universidade Federal do Rio Grande do Sul. Porto Alegre, 1988.

IANTAS, L. C. Estudo de caso: Análise de patologias estruturais em edificações de gestão pública. 2010. $58 f$. Trabalho de Conclusão de Curso (Graduação) - Curso de Pós- Graduação em Construção de Obras Públicas. Universidade Federal do Paraná. Curitiba, 2010.

HELENE, P. R. L. Manual de reparo, proteção e reforço de estruturas de concreto. São Paulo. Red. Rehabilitar, 2003.

LIMA, A.C.S. Manifestações patológicas nas edificações escolares da rede municipal de Criciúma: Levantamento e análise sobre a recorrência. 161f. Trabalho de Conclusão de Curso (Graduação), Curso de Engenharia Civil. Universidade do Extremo Sul Catarinense. Criciúma, 2010.

OLIVEIRA, D. F. Levantamento de causas de patologias na construção civil. Trabalho de Conclusão de Curso (Graduação), Curso de Engenharia Civil. Universidade Federal do Rio de Janeiro. Rio de Janeiro, 2013.

OLIVEIRA, A.M. de S. S. Patologia das edificações. Apostila do Curso de Engenharia Civil. Centro de Ciências Exatas e Tecnológicas. Universidade Estadual do Oeste do Paraná. 2015.

SEGAT, G.T. Manifestações Patológicas observadas em revestimentos de argamassa: Estudo de caso em um conjunto habitacional popular na cidade de Caxias do Sul (RS). Dissertação (Mestrado) - Curso de Engenharia Civil. Universidade Federal do Rio Grande do Sul. Porto Alegre, 2005.

SCHARDONG, G. K.; PAGNUSSAT, D. T. Avaliação de manifestações patológicas em edificações escolares públicas. Patologia das Construções. CINPAR. Fortaleza, 2011.

ZUCHETTI, P. A. B. Patologia da construção civil: Investigação patológica em edifício corporativo de administração pública no vale do Taquari/RS. 2015. 128f. Trabalho de Conclusão de Curso (Graduação) - Curso de Engenharia Civil. Centro Universitário Univates. Lajeado, 2015. 